\title{
Realization of Distribution Network Feeder Terminal Unit based on Dual-DSP
}

\author{
Yunjuan $\mathrm{Li}^{1 *}$, Fanrong Wang2* \\ ${ }^{1}$ Kunming University, Kunming 650214, Yunnan, China; \\ ${ }^{2}$ School of Electric \& Electronic Engineering, Hubei University of Technology, Wuhan 430068, Hubei Province, China
}

\begin{abstract}
This paper presents the design proposal of distribution network monitoring unit based on dual-DSP. A detailed description of the hardware structure about the device is introduced which including signal scheduling, SPI communication, the serial human-computer communication and network communication. Additionally, the paper describes the software process about the master and slave DSPs. Then the analog precision test and the protection response test are carried out. The result shows that the design proposal is correct.
\end{abstract}

Keywords: Dual-DSP; Distribution Network; Monitoring unit; Signal Scheduling

Publication date: March, 2021; Publication online: 31 March, 2021

*Corresponding author: Yunjuan Li, linda220603@126.com; Fanrong Wang,wfr@mail.hbut.edu.cn

\section{Introduction}

Based on the increasing demand for electricity of our country, gradually ageing distribution system will not meet the power supply reliability and quality to the national industrial economic and the people's daily life. Once the faults occurred, rapid fault diagnosis and shorten outage time is significant, which could improve supply reliability and safety and decrease economic losses.

As core equipment, FTU (feeder terminal unit) plays a particularly important role in distribution automation system, which is also the focus of this study. In view of the FTU device characteristics which includes quick sampling speed, large amount data calculation, high real-time requirements, and frequent communication with the distribution master station, this article presented an intelligent design proposal of FTU based on dual-DSP.

The remainder of this paper is organized as follows. Section 2 describes system project design. Section 3 analyses some key parts of the system. Section 4 shows field test results. Finally, some concluding remarks along with open research issues are proposed in section 5.

\section{System Design}

We use DSP and microcontroller structure ${ }^{[1]}$ in the previous design of FTU. The single chip collects the AC signal and sends it to DSP. There is insufficient time to response. Thus, we use dualDSP structure and FTU's overall structure is shown in Figure 1.

Software functions are divided into re-closing action, SPI data communications, serial communication and network communication. Reclosing action is that the FTU as an intelligent switch deals opening or closing process under the appropriate condition. SPI data communication is to send the information obtained from the slave DSP to master DSP. Serial communication is that the FTU as on-site machine finishes its data display with its own LCD screen, as well as functional data setting. Network Communication considers FTU as a node of the network. And the switch signals and other data signals are recorded on the distribution network. Then the network can control the FTU node remotely.

It is the master DSP software flow: when FTU starts, it follows the unilateral coincidence rules. Then getting data obtained from the slave DSP, 
uploading to web and screen, processing fault waiting for the network and the serial port diagnosis according to the protection logic, and instructions.

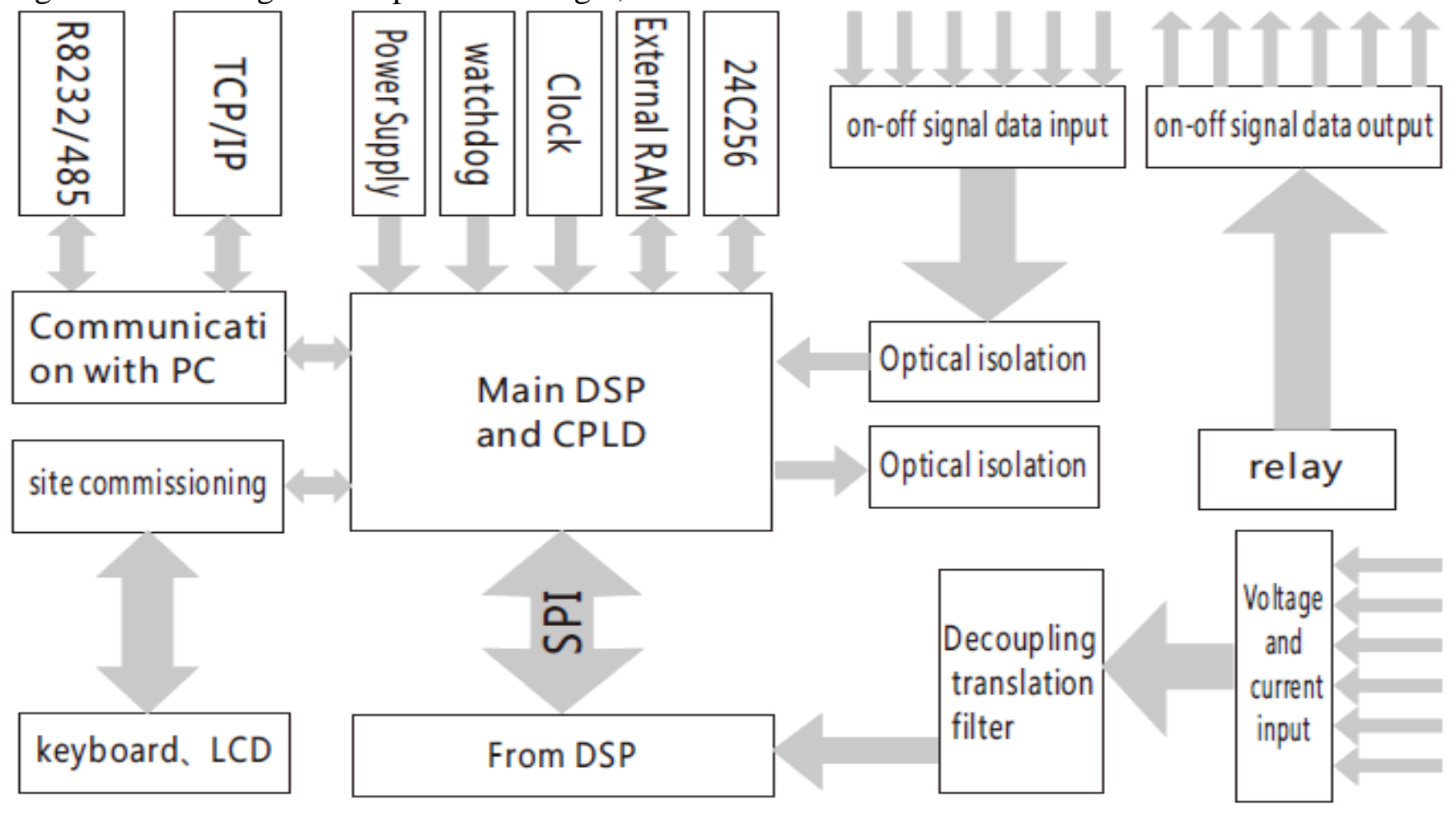

Figure 1. FTU's overall structure

\section{Some Key Parts of the System}

\subsection{FTU hardware structure}

Hardware part is mainly composed of chassis, bottom board, screen and keyboard, master CPU plug-in unit, AC sampling plug-in unit, remote signal plug-in unit, remote control plug-in unit, power plug-in unit, as well as part of the composition.

Utilizing the slot structure ${ }^{[2]}$, the bottom board has a power bus, an address bus and a data bus and connects the plug-in units. Each plug-in unit has relatively independent function. There are 14 slots on the bottom board. The first is power plug-in slot, the second is master CPU plug-in slot, and the remaining 12 slots can be configured as $\mathrm{AC}$ sampling plug-in slot or remote control plug-in slot, the system has a strong scalability. Figure 2 FTU's hardware structure and the main plug-in units are introduced as below.

\subsection{Signal Scheduling}

The system uses CPLD chip XC9536 in Xilinx Corporation to process the data transmission between CPU plug-in unit and AC sampling plugin unit, remote signal plug-in unit, remote control plug-in unit. XC9536 primarily consists of the following three modules: function module, the I/O interface module and the interconnect matrix module ${ }^{[3]}$. Among them, the function module realizes the CPLD logical processing, the I/O module provides CPLD the input and the output cushion, the interconnection matrix realizes the CPLD interior signal momentary connection ${ }^{[4]}$. Figure 3 shows the connection diagram of system signal scheduling.

The CPU signal scheduling procedure is as follows: When the CPU needs the data of the AC sampling plug-in unit, it will first notify the CPLD to select this plug-in latch, so the plug-in can connect its data bus to the CPU data bus, and the other plug-ins cannot be connected. After the operation, CPLD control the plug-in latch to isolate its data bus from the CPU data bus. Thus, the CPU can control any plug-in unit without affecting the other plug-in units, and it can finish signal scheduling perfectly. 


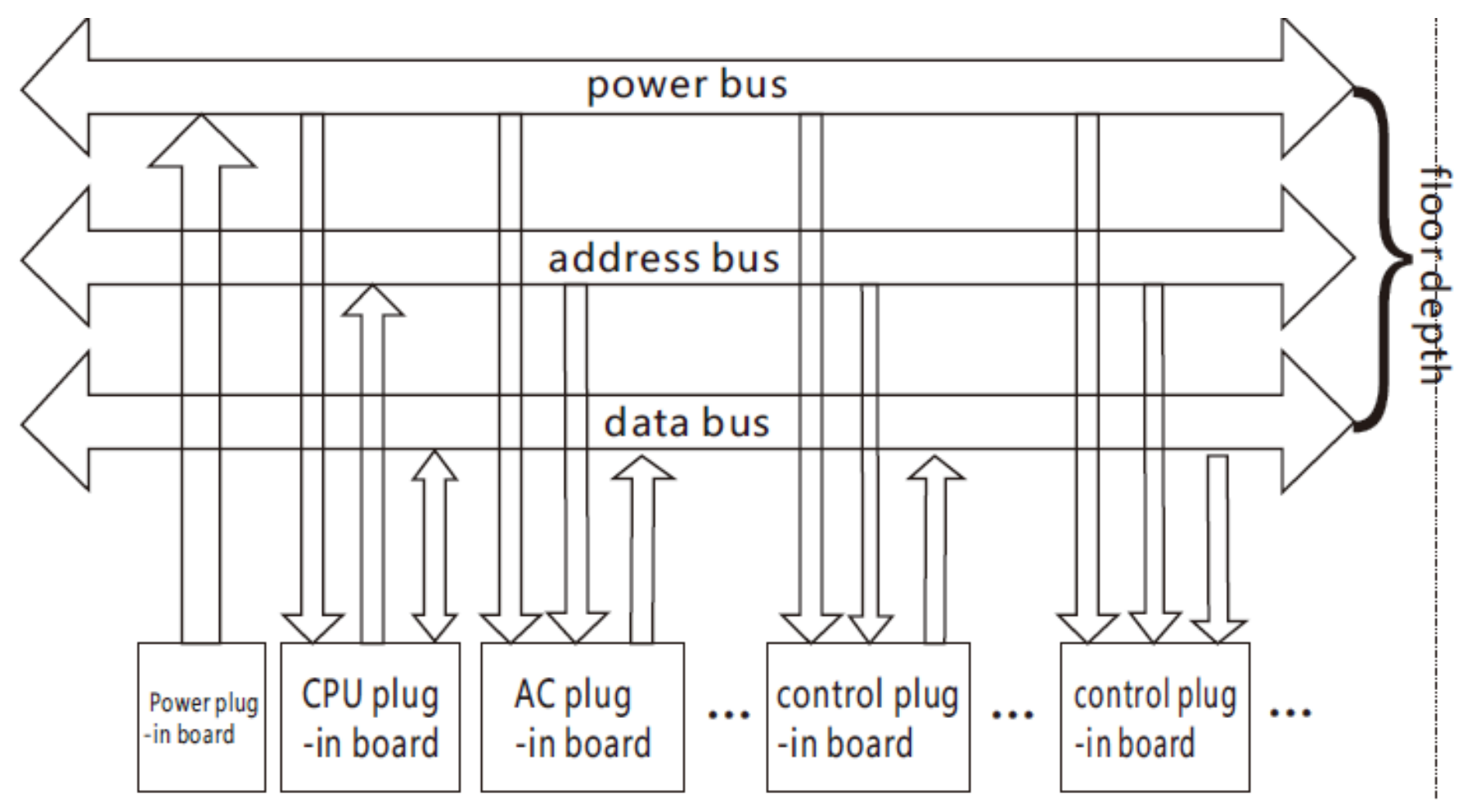

Figure 2. FTU's hardware structure and the main plug-in units

\subsection{SPI Communication}

The Serial Peripheral Interface (SPI), has introduced a high-speed, full-duplex synchronous serial communication bus ${ }^{[5]}$. It works in master/slave mode, supporting a master device to communicate with one or more salve devices. Its pins on the chip take up only four lines, namely: SDI, SDO, SCK and CS. SCK is a system serial communication clock signal which is controlled by the master device. SDI and SDO are data input and output pins, which is based on the square wave signal of SCK to complete the data transmission. $\mathrm{CS}$ is the enable pin of the slave device which is controlled by CPLD ${ }^{[6]}$.

Figure 4 is the SPI communication hardware connection diagram of master -slave DSPs. The CS strobe of salve DSP is controlled by the CPLD. When the CS signal of the slave device is low, the chip can receive data on the SPI or send data to the SPI bus. SPI is a full-duplex communication, allowing data input and output at the same time.

SPI program flow is as follows: slave DSP opens a data buffer in the program to store the computed data after Analog-to-digital converter (ADC) module sampling. AC sampling plug-in unit uses the slave DSP to sample the voltage and current data, and then convert these data into effective value. When the master DSP needs data, it enables the slave DSP to translate with it. After receiving data, the master DSP firstly determines whether the received data is valid data or not by the header, then determines whether it is a valid command header or data header. After calibration, the master DSP continue the remained steps according to the SPI program flow shown in Figure 5.

\subsection{Local machine communication}

This system uses the LCD screen based on the RS232 interface and DSP to finish the local machine communication. Users can easily see the feeder lines running stats, analog measurement and switch situation on spot. And users can operate the switch via key buttons. It uses the SCI module of S3C2440A chip ${ }^{[7]}$ whose GPIOH interfaces can be used as serial communication port. It use the MAX232 to complete the system level conversion betweenRS232 and TTL. Figure 6 is showing the connection diagram between S3C2440A and MAX232. As well as LCD software menu structure 
is shown in Figure 7.

Real-time data menu contains real-time analog circuit data and switch data, and the digital input and relay output display screen are shown in Figure 8. Value setting menu contains setting and viewing the relay logic parameters, authorized users can easily adjust some FTU relay logic through the menu, and these parameters can be uploaded to distribution main station. Additionally, this interface provides an event logging on the system. Users can find what time and what type of relay protection action that the FTU had started over through this menu, helping maintenance person to find the cause of the failure, providing the basis for excluding line fault. Figure 9 is showing the picture of the FTU value setting and event logging interface.

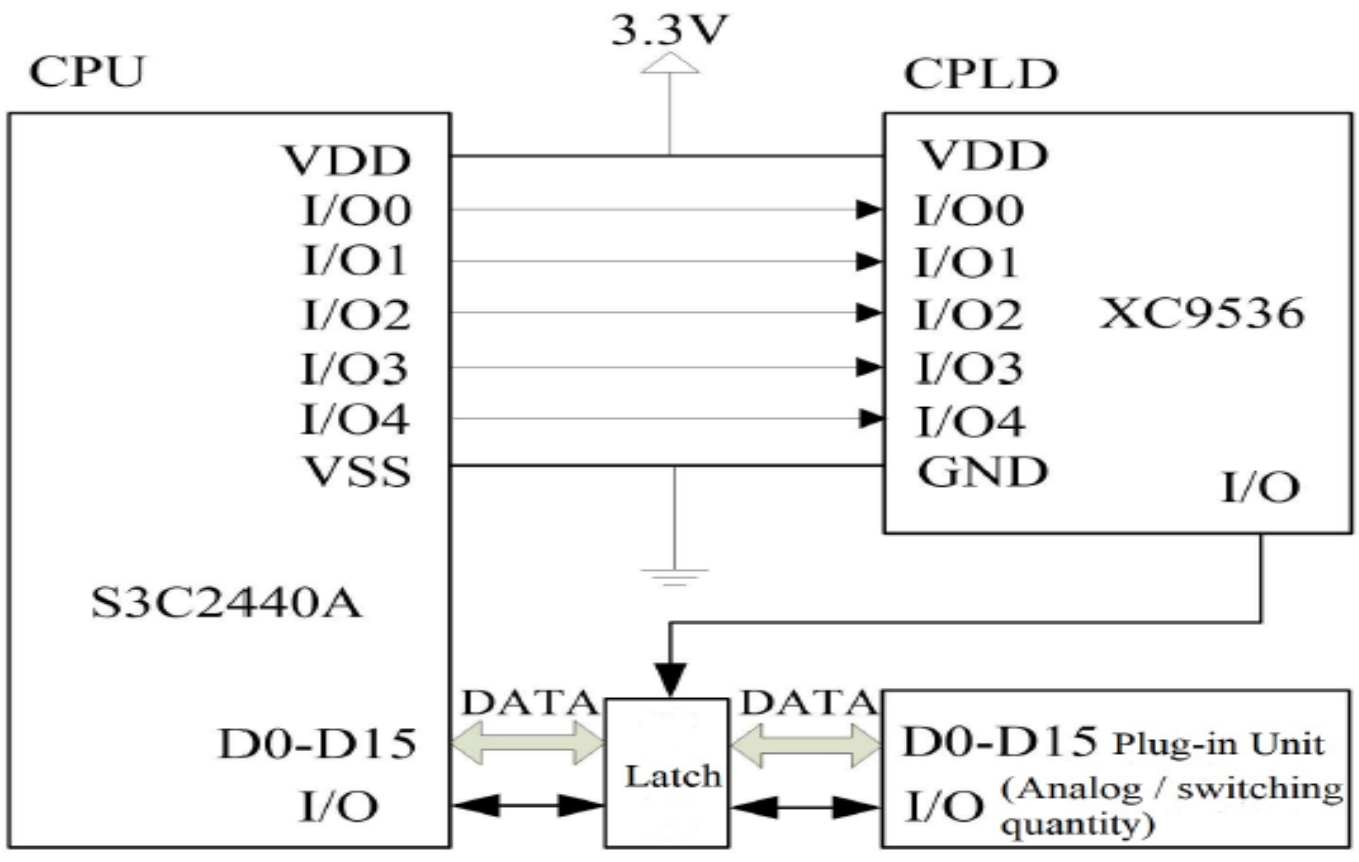

Figure 3. Signal scheduling connection diagram

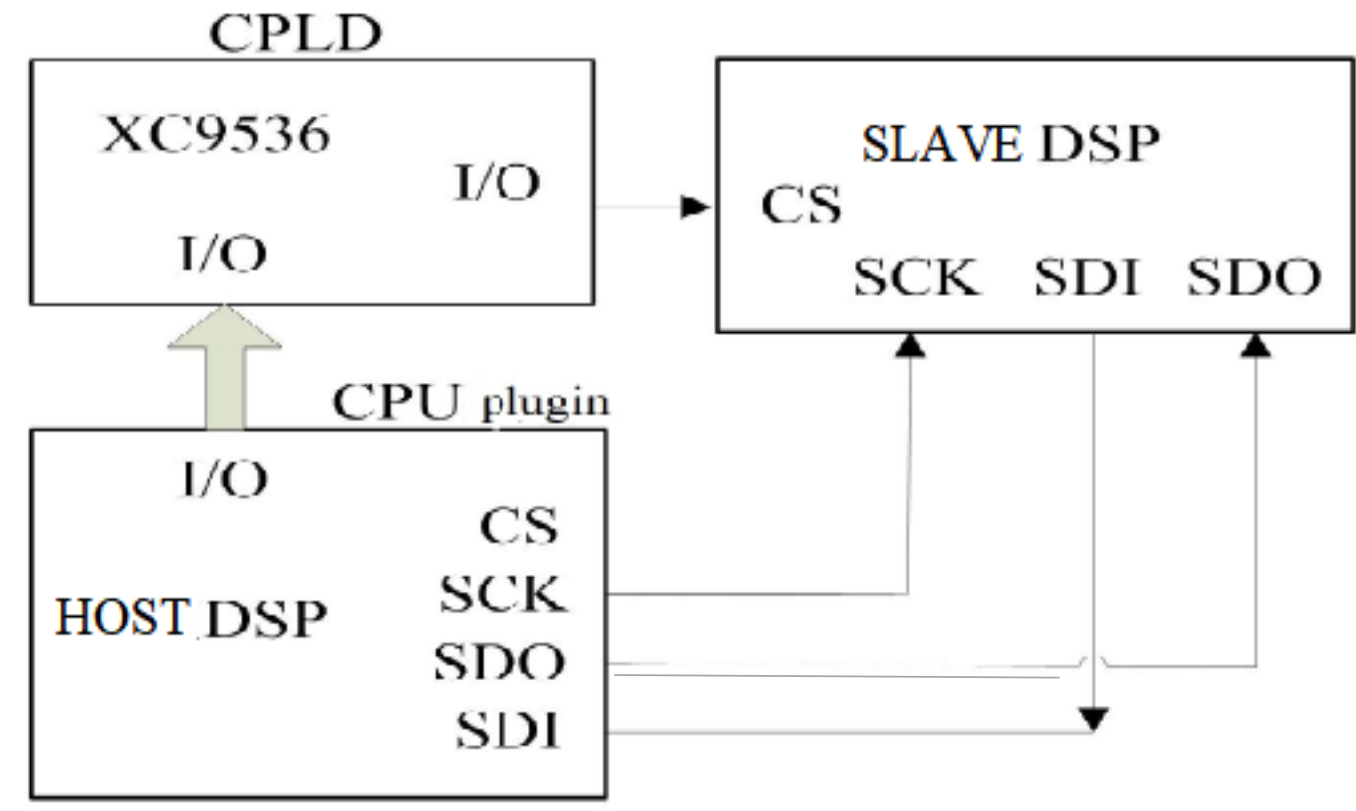

Figure 4. SPI connection of Master-slave DSPs 


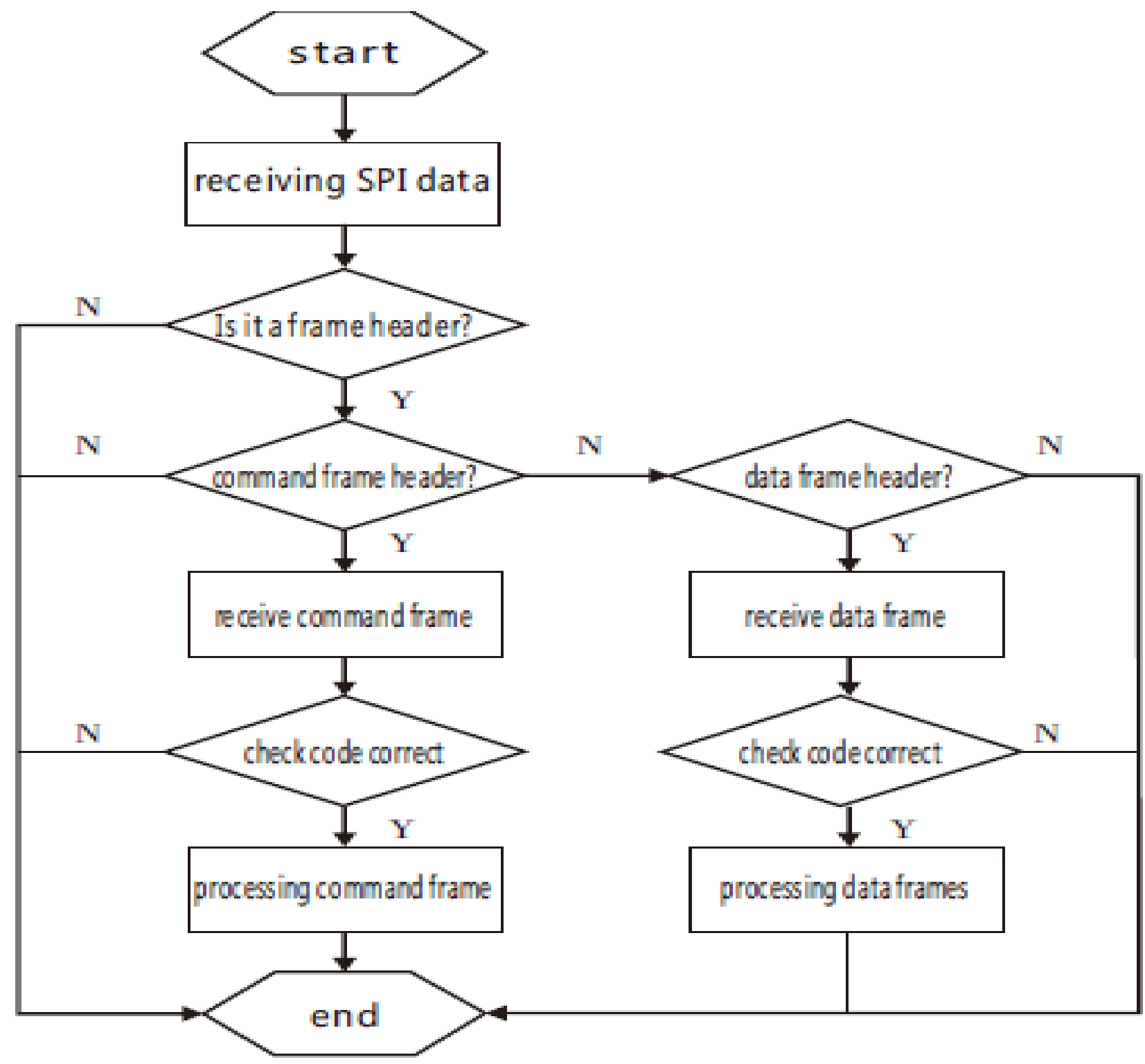

Figure 5. SPI program flow

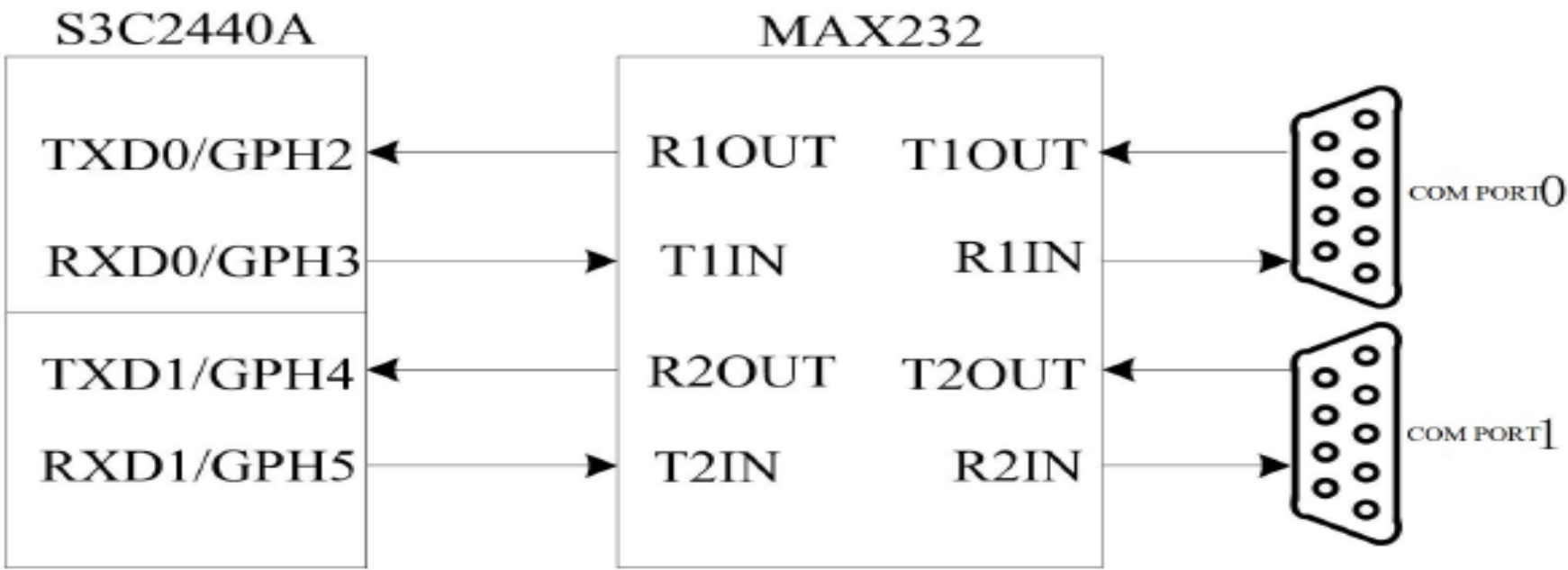

Figure 6. Local machine hardware connection 


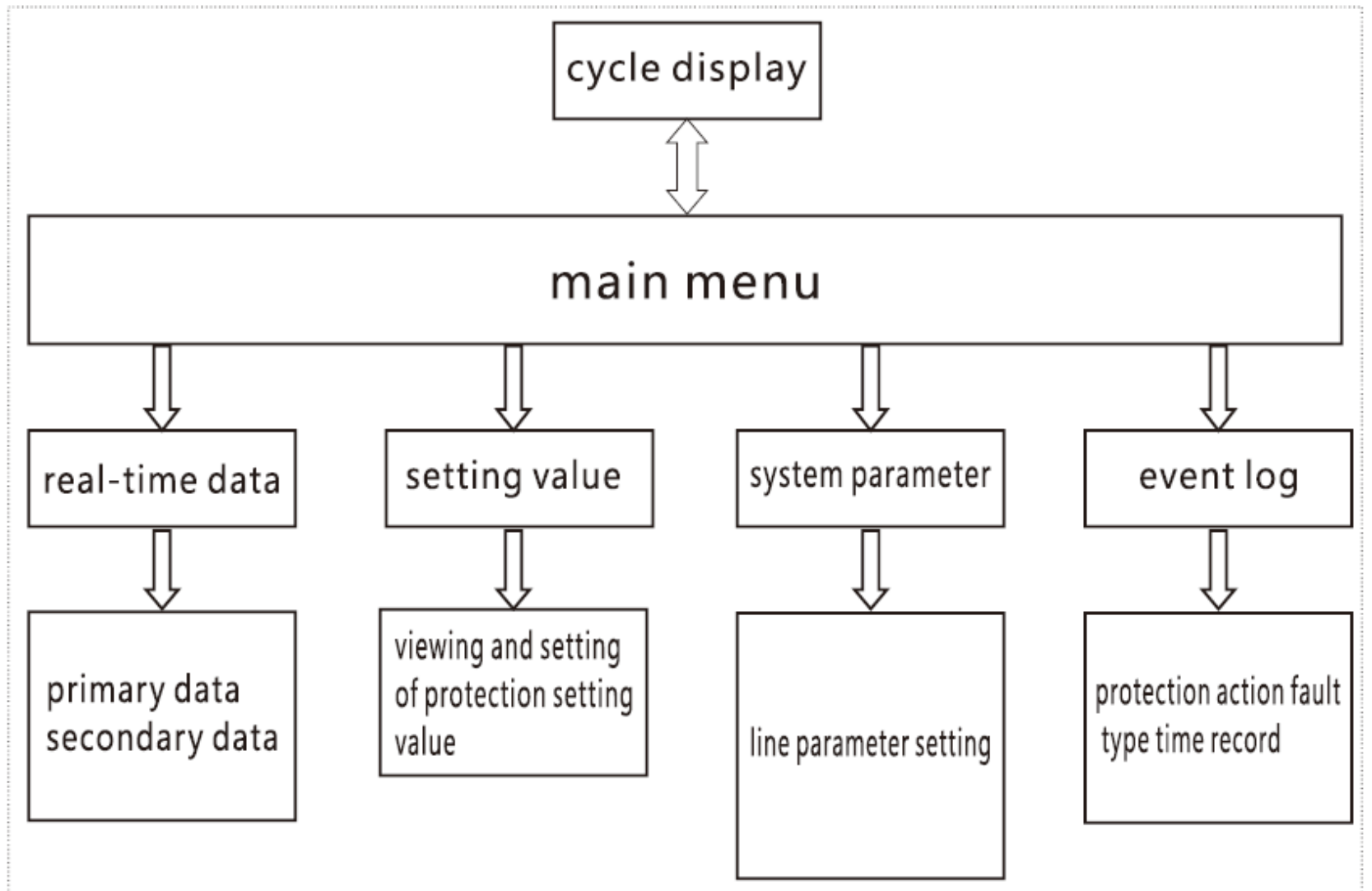

Figure 7. LCD software menu structure

\begin{tabular}{|c|c|c|}
\hline $\begin{array}{lr}\text { monitor 1a: } & \mathbf{5 1 . 0} \\
\text { monitor 1b: } & \mathbf{6 0 . 0} \\
\text { monitor 1c: } & \mathbf{5 9 . 0} \\
\text { monitor Uab: } & \mathbf{2 1 . 3} \\
\text { monitor Ubc: } & \mathbf{2 . 0} \\
\text { monitor Uac: } & \mathbf{3 . 9}\end{array}$ & $\begin{array}{l}\mathrm{mA} \\
\mathrm{mA} \\
\mathrm{mA} \\
\mathrm{V} \\
\mathrm{V} \\
\mathrm{V}\end{array}$ & $\begin{array}{lrl}\text { system power: } & \mathbf{5 0 . 0 1} \mathrm{Hz} \\
\text { active power: } & \mathbf{1 2 . 0} \mathrm{Kw} \\
\text { reactive power: } & \mathbf{1 1 3 . 0 \mathrm { Kw }} \\
\text { Power factor: } & \mathbf{0 . 1} \\
\text { Communication status: normal } \\
\text { Opening and closing status: closing }\end{array}$ \\
\hline $\begin{array}{l}\text { Automatic/ Manual: } \\
\text { Switch position: } \\
\text { Energy storage location: } \\
\text { Position of disconnector (1): } \\
\text { Position of disconnector (2 ) } \\
\text { Earthing switch: } \\
\text { Heavy gas trip: } \\
\text { Light gas trip: }\end{array}$ & $\begin{array}{l}1 \\
1 \\
1 \\
1 \\
1 \\
1\end{array}$ & $\begin{array}{l}\text { No.1 relay: } \\
\text { No.2relay: } \\
\text { No.3relay: } \\
\text { No.4relay: } \\
\text { No. } 5 \text { relay: } \\
\text { No.6relay: } \\
\text { No.7relay: }\end{array}$ \\
\hline
\end{tabular}

Figure 8. Real-time data display 


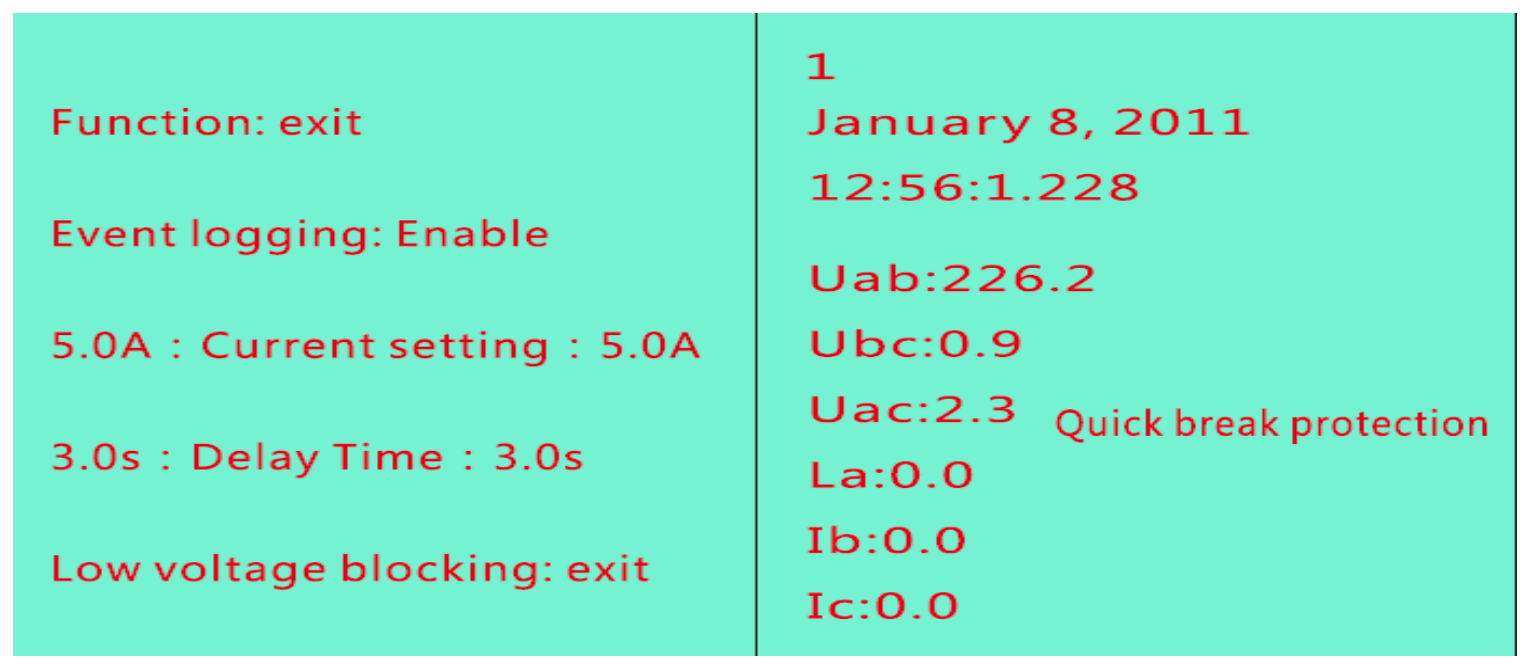

Figure 9. FTU value setting and event logging interface.

\section{Test data and analysis}

On the ZD43 relay protection test instrument platform, this article mainly tests analog measurement precision, logical reaction and tripping speed.

\subsection{Analog measurement precision test}

Voltage, current, frequency measurements are shown as table 1. Voltage absolute error of this FTU system is less than 1V. Current absolute error is less than $0.5 \mathrm{~A}$. The relative error is smaller than $2 \%$. Because the FTU used the DSP capture unit to measure Frequency, it has obtained a higher precision, the absolute error is smaller than $0.05 \mathrm{~Hz}$, and the relative error is smaller than $0.1 \%$. Furthermore, active/reactive power, power factor and other parameters are measured, and the experiment results show that the FTU will meet the appropriate requirements

Table 1. FTU measurement data

\begin{tabular}{|l|l|l|l|l|l|}
\hline No. & Parameter Type & $\begin{array}{l}\text { Standard } \\
\text { Value }\end{array}$ & Measurements & Absolute Error & $\begin{array}{l}\text { Relative } \\
\text { Error (\%) }\end{array}$ \\
\hline 1 & Voltage & $5 \mathrm{~V}$ & $4.92 \mathrm{~V}$ & $0.08 \mathrm{~V}$ & 1.6 \\
\hline 2 & Voltage & $10 \mathrm{~V}$ & $10.14 \mathrm{~V}$ & $0.14 \mathrm{~V}$ & 1.4 \\
\hline 3 & Voltage & $20 \mathrm{~V}$ & $19.90 \mathrm{~V}$ & $0.1 \mathrm{~V}$ & 0.5 \\
\hline 4 & Voltage & $50 \mathrm{~V}$ & $49.81 \mathrm{~V}$ & $0.19 \mathrm{~V}$ & 0.38 \\
\hline 5 & Voltage & $100 \mathrm{~V}$ & $100.86 \mathrm{~V}$ & $0.86 \mathrm{~V}$ & 0.86 \\
\hline 6 & Current & $0.5 \mathrm{~A}$ & $0.51 \mathrm{~A}$ & $0.01 \mathrm{~A}$ & 2 \\
\hline 7 & Current & $1 \mathrm{~A}$ & $1.01 \mathrm{~A}$ & $0.01 \mathrm{~A}$ & 1 \\
\hline 8 & Current & $5 \mathrm{~A}$ & $4.96 \mathrm{~A}$ & $0.04 \mathrm{~A}$ & 0.8 \\
\hline 9 & Current & $10 \mathrm{~A}$ & $9.92 \mathrm{~A}$ & $0.08 \mathrm{~A}$ & 0.8 \\
\hline 10 & Current & $40 \mathrm{~A}$ & $39.62 \mathrm{~A}$ & $0.38 \mathrm{~A}$ & 0.95 \\
\hline 11 & Frequency & $50 \mathrm{~Hz}$ & $49.98 \mathrm{~Hz}$ & $0.02 \mathrm{~Hz}$ & 0.04 \\
\hline 12 & Frequency & $60 \mathrm{~Hz}$ & $60.03 \mathrm{~Hz}$ & $0.03 \mathrm{~Hz}$ & 0.05 \\
\hline
\end{tabular}




\subsection{Protection action response test}

Relay protection, there is a quick-break protection, extension speed of trip protection, over-current protection, over voltage and low voltage protection and other protection logic. In the designing of FTU, the protection objective is that when external input signals comply with these conditions of protection logic, FTU can quickly drive on the remote control plug-in relays to trip or closing, so that external electrical equipment, such as circuit breakers, produce an appropriate opening actions in order to achieve the goal of fault isolation or line status adjustment.

Current protection test data can be seen in the above table, FTU action error between current value and setting value is less than $3 \%$. It meets the requirement of less than $5 \%$ in relay protection action, and current instantaneous response time is less than 40ms which included the remote control panel relay inherent pull-in time.

Table 2. Current protection test data

\begin{tabular}{|c|c|c|c|c|c|}
\hline No. & $\begin{array}{l}\text { Quick } \\
\text { determination } \\
\text { value } \\
(\mathrm{A})\end{array}$ & $\begin{array}{c}\text { Responding } \\
\text { Value (A) }\end{array}$ & $\begin{array}{c}\text { Returned } \\
\text { Value (A) }\end{array}$ & $\begin{array}{c}\text { Relative } \\
\text { Error (\%) }\end{array}$ & $\begin{array}{c}\text { Responding } \\
\text { Time (ms) }\end{array}$ \\
\hline 1 & 5 & 5.05 & 4.95 & 1 & 37.473 \\
\hline 2 & 5 & 5.10 & 4.95 & 2 & 32.565 \\
\hline 3 & 10 & 10.10 & 10.00 & 1 & 37.824 \\
\hline 4 & 10 & 10.10 & 9.90 & 1 & 31.971 \\
\hline 5 & 20 & 20.40 & 20.00 & 2 & 30.468 \\
\hline 6 & 20 & 20.20 & 19.80 & 1 & 32.579 \\
\hline 7 & 50 & 50.00 & 49.00 & 0 & 31.853 \\
\hline 8 & 50 & 50.50 & 49.50 & 1 & \\
\hline
\end{tabular}

\section{Conclusion and Discussion}

This article proposed dual-DSP SPI communication design in view of the FTU characteristics. It used the slot type structure in the overall design. By carrying on the test on the ZD43 (which is a model of electric motor driven relay protection test system) relay protection reflect scope reflector, it confirmed that the design is correct and it may be used in state grid ${ }^{[8]}$.

Successful application of the FTU will make greater contributions to distribution network fault location and recovery. In the current distribution network fault diagnosis methods such as matrix algorithm and artificial intelligence algorithm, their preconditions are assumed that they got a large number of nodes information in the distribution, and then made the theoretical derivation and simulation calculations, and they largely didn't take into account the actual site status. If this FTU is used, the underlying data source of various distribution network's fault diagnosis algorithms may no longer came from the assumption sand simulation.

\section{Disclosure statement}

The author declares no conflict of interest.

\section{References}

[1] Zhou H., Luo X., Deng Q (2011). Design of DSP-based FTU for RMU of Intelligent Distribution Grid[J]. Electric Power Automation Equipment, 31(2):124-128.

[2] Zhou H., Luo X., Deng Q (2010). The Design and Development of DSP Based Ring Main Unit FTU in Intelligent Distribution. 2010 The International Conference on Electrical and Control Engineering

[3] Cai S (2005). Research and development of intelligent ring main unit of control measuring and 
protection $[\mathrm{J}]$, Electric Power Automation Equipment, 25(2):24-25

[4] Zhou N., Jia Y., Zhao Yuan (2006). Feeder terminal unit based on system protection to distribution network[J], Automation of Electric Power System, 30(8):94-97

[5] Sood K., Fischer D., Eklund JM., et al. (2009). Developing a Communication Infrastructure for the Smart Grid[C], IEEE Electrical Power \& Energy Conference, 1-7

[6] Purucker SL., Thomas RJ., Monteen LD. (2007), Feeder Automation Designs for Installing an Intergrated Distribution Control System[J], Power Apparatus and System, IEEE Transactions, 104(10):2929-2934

[7] Teng JH., Lu CN. (2006), Value-based distribution feeder automation planning[J]. International Journal of Electrical Power and Energy Systems, 28(3):186-194.

[8] Wada K., Fujita H., Akagi H. (2006), Considerations of a Shunt Active Filter Based on Voltage Detection for Installation on a Long Distribution Feeder[J]. IEEE Transactions on Industry Applications, 38(4):1123-1130. 